\title{
Defective Utilization of Sensory Input as the Basis for Bradykinesia, Rigidity and Decreased Movement Repertoire in Parkinson's Disease: A Hypothesis
}

\author{
W.G. Tatton, M.J. Eastman, W. Bedingham, M.C. Verrier and I.C. Bruce
}

\begin{abstract}
From a review of the anatomical relationships and single unit activity in the components of the basal ganglia related to limb movement, it is concluded that the major outflow from basal ganglia circuits is via the motor cortex (area 4). Recent results of recording from area 4 neurons revealed that they preferentially "encode" the higher derivatives of movement, i.e. acceleration and jerk. In the parkinsonian (PK) patient and in the monkeys treated with 1-methyl-4-phenyl-1,2,3,6-tetrahydropyridine (MPTP), EMG responses to imposed loads show a markedly increased gain of the "M2" component which depends upon the integrity of area 4 and which correlates with the severity of PK rigidity.

The above observations are considered, along with those of others (demonstrating prolonged movement times, a decreased "repertoire" of voluntary movements fractionation of voluntary movements; inability in tracking movements without visual input, and failure to improve performance in PK's) in relation to a model of the interactions between sensory input and motor programs. Using this model, it is hypothesized that the above PK movement deficits, as well as rigidity, can be accounted for by abnormal processing of the mechanoreceptor sensory input utilized in the generation and execution of movements. The MPTP treated monkey is suggested as a model in which to directly test the hypothesis.
\end{abstract}

RÉSUMÉ: Une revue des relations anatomiques et de l'activité mono unitaire des differérentes parties des noyaux gris centraux reliées au mouvement nous permet de conclure que l'efférence principale des circuits des noyaux de la base est à travers le cortex moteur (aire 4). Ces neurones "encodent" préférentiellement les dérivés supérieurs du mouvement, l'accélération et le mouvement brusque. Chez le Parkinsonien (PK), comme chez le singe traité au 1-méthyl-4-phényl-1,2,3,6-tétrahydrophyridine (MPTP), les réponses EMG à des poids imposés montrent un gain augmenté de la composante "M2", laquelle dépend de l'intégrité de l'aire 4 et laquelle est en correlation avec la sévérité de la rigidité chez le Parkinsonien.

A la lumière de ces observations et de plusieurs autres (temps de mouvement prolongés, répertoire diminué de mouvements volontaires, fractionnement de ces mouvements volontaires, inabilité de suivre les mouvements sans input visuel et inabilité d'améliorer la performance des PK), nous considérons un modèle de l'interaction entre l'input sensoriel et les programmes moteurs. Ces mouvements du PK, déficits et rigidité, peuvent être expliqués par une utilisation anormale de l'input sensitif des mécanorécepteurs employés dans la génération et l'exécution des mouvements. Le modèle MPTP chez le singe devrait permettre de vérifier cette hypothèse.

Can. J. Neurol. Sci. 1984; 11:136-143

\section{Background}

During the early decades of this century most investigators considered that coordinated movements resulted from the sequential activation of reflexes. According to those concepts reafferent sensory input from peripheral mechanoreceptors was essential to the evolution of movements. The demonstration of so called "command interneurons" in invertebrate motor systems in the 1960's and popularization of the notion of centrallypatterned motor programs shifted conceptual emphasis away from reflex systems (see Kupfermann and Weiss, 1978 for a review of the tenets underlying the command interneuron hypothesis). The concepts have been extended to mammalian systems as neurons purported to be homologous with invertebrate command interneurons have been reported in the primate parietal association cortex (Mountcastle et al., 1975).
Deafferentation experiments in subhuman primates have supported the role of central patterns in determining the evolution of coordinated limb movements but also have revealed decreased levels of performance apparently due to the loss of sensory feedback from mechanoreceptors (Taub and Berman, 1968; Taub et al., 1975; Gilman et al., 1976). Accordingly, one school of thought has proposed that mechanoreceptor-evoked reflexes function in a servo-assistance mechanism for load compensation (Marsden et al., 1972 and 1976; also see Allum, 1976) and thereby serve to automatically correct for "unexpected programming errors" during movement execution. In contrast, studies of electromyographic activity and the activity of motor cortical neurons during ballistic movements in deafferented monkeys have shown the relationship between specific movement variables and motor cortical activity to be retained for high- 
velocity movements carried out by a deafferented limb (Lamarre et al., 1978). This and other research has shown that mechanoreceptor input is essential to the evolution of motor programs for some movements and is less influential in other (e.g. ballistic) movements involving the same musculature. In fact, the precise role of mechanoreceptor input in movement control remains to be determined.

Parkinsonian (PK) patients present a constellation of motor deficits, none of which are understood in terms of dysfunctions involving specific populations of neurons within the central nervous system. Neurochemical studies have established degeneration of dopaminergic neurons projecting from the substantia nigra compacta (labelled $\mathrm{SN}_{\mathrm{c}}$ in figure 1) to the caudate and the putamen (collectively labelled STRIATUM in figure 1) as a fundamental element in the genesis of the syndrome (Hornykiewicz, 1963 and also see Schultz 1982 for a review of striatal dopamine depletion models). To date, researchers recording the activity of $\mathrm{SN}_{\mathrm{c}}$ neurons in trained monkeys performing a variety of motor acts have not found any evidence that the $\mathrm{SN}_{\mathrm{c}}$ plays a role in programming or initiating movements (see DeLong et al., 1983; Schultz 1983 for recent studies and pertinent references). This is in sharp contrast to neurons in the putamen, the two pallidal segments ( $\mathrm{PE}$ and $\mathrm{PI}$ in figure 1), and the subthalamic nucleus (Sth in figure 1), each of which has been shown to contain topographically-organized neurons whose activity occurs before a variety of motor acts (indicating those structures are involved in the initiation and/or the programming of movements). Furthermore, neurons in those structures receive input from peripheral mechanoreceptors (see DeLong et al., 1983; Georgopoulos et al., 1983; Liles, 1983; for recent examples together with DeLong and Georgopoulos 1981 for a review). Hence, at present the neuronal population whose loss appears to be the major factor underlying PK movement deficits, that is the $S N_{c}$, has not been shown to be related to movement generation (see Lee, this volume).
Figure 1 - Schematic illustration of the relationships of the basal ganglia to motor output structures. The arrowsindicate pathways between structures, and their widths approximate the strength of the connections (defined in upper left). CM: centromedian nucleus of thalamus; Hab: habenula and other limbic structures; $\mathrm{Pi}, \mathrm{Pe}$ : globus pallidus internus, externus: Ret: reticular nuclei; $S C$ : superior colliculus; $S N_{c}, S N_{R}$ : substantia nigra compacta, reticulata; SMA: supplementary motor area; Sth: Subthalamic nucleus; TPC: pedunculopontine nucleus; VA, VL: ventroanterior and ventrolateral nucleus of thalamus. See text for further details.

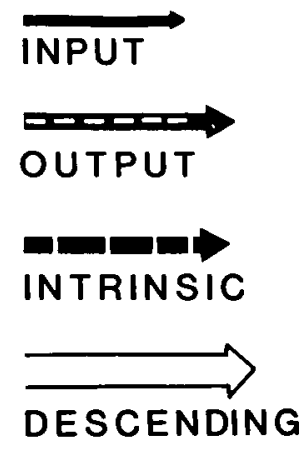

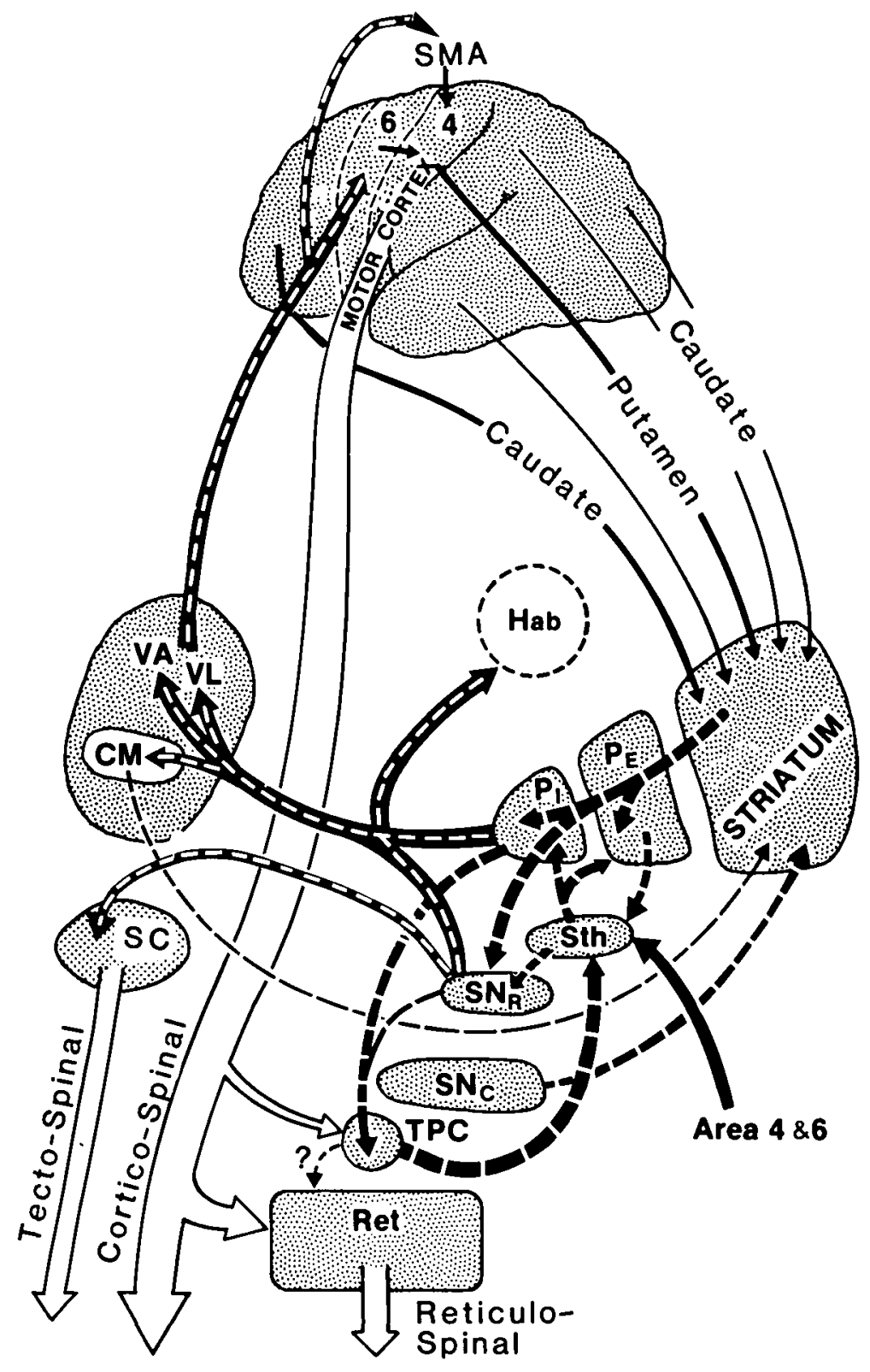


As well as summarizing the intrinsic internuclear connections of the basal ganglia pertinent to movement control in primates, figure 1 presents several relevant concepts regarding basal ganglia input and output connections:

1) Association cortical areas project predominantly to the caudate nucleus while the motor cortex (area 4) and the somatosensory cortex (areas 3, I and 2) project to the putamen, which has been shown to contain neurons whose activity is strongly movement-related. Therefore putative "command interneurons" (see above) reported to be located in the parietal association cortex are not in a position to directly influence those basal ganglia structures related to movement control.

2) The subthalamic nucleus receives topographically-organized projections from area 4 and area 6 (the premotor cortex).

3) The pallidal outflow to the VA-VL thalamus projects to portions of the thalamus apparently separate from those receiving deepcerebellar nuclear input (Strick, personal communication). In turn, those thalamic areas do not send axons directly to the motor cortex (area 4), rather, they project to the premotor cortex (area 6) and the supplementary motor area (SMA, see Weisendanger 1981 for a review of the connections and proposed functions of these areas in the preparation for and generation of motor programs). In turn, area 6 and SMA send strong projections to the motor cortex (area 4) which, therefore represents the major descending motor outflow of the basal ganglia. Importantly, the pedunculopontine nucleus in the upper brain stem (TPC in figure 1), which had previously been regarded as a major descending outflow of the basal ganglia, appears to send few, if any, direct terminals to the portions of the reticular formation known to project to the spinal cord (H. Nauta, personal communication). Accordingly, any models attempting to relate dopamine depletion in the movement-related areas of putamen to abnormal motor activity involving the limbs, either centrally programmed or reflex in nature, must consider area 4 as the major origin of the abnormal descending activity.

4) The reticular portion of the substantia nigra $\left(\mathrm{SN}_{R}\right.$ in figure 1) is now recognized to form part of the pallidal complex and contains neurons whose activity is related to eye and head movements. The $\mathrm{SN}_{\mathrm{R}}$ projects to the deep layers of the superior colliculus (SC in figure 1) which in turn project to the upper cervical cord by way of the tecto-spinal tract.

In short then, despite our increasing knowledge of the connective organization of the basal ganglia, its transmitter organization (see McGeer, this volume) and the activity of specific movement-related neurons within subregions of its different nuclei, as well as the related input and output structures, we cannot, at present, begin to translate that information into one or more coherent pathophysiologic models relating loss of $\mathrm{SN}_{\mathrm{c}}$ neurons to Parkinsonian movement deficits.

\section{Abnormal Mechanoreceptor-Evoked Reflexes in PK Rigidity}

Imposed angular joint movements, similar to those used by clinicians to test muscle tone, evoke segmented EMG activity in the stretched muscles. A vast and controversial literature surrounds the origins of the short (M1) and long latency (M2-3) segments of the mechanoreceptor-evoked reflexes (MERs, see Lee and Tatton, 1982 and Wiesendanger and Miles, 1982 for recent references). Recent research in subhuman primates has established that neurons in the motor cortex (area 4) must contribute to the generation of the M2-3 segment in the
Magnitude Reflex

EMG Evoked by Imposed Movements

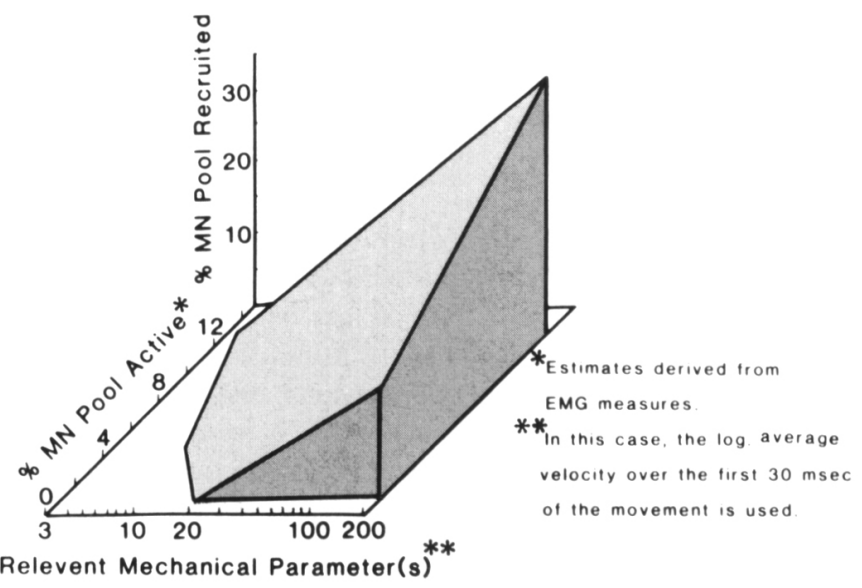

Figure 2 - Schematic illustration of a "response plane" from average data in a normal subject to illustrate the method of displaying motoneuron $(M N)$ reflex activity ( $Y$ axis) over a range of mechanical inputs ( $X$ axis) and background $M N$ activity ( $Z$ axis).

musculature of the distal upper limb (see Lenz et al., $1983 \mathrm{a} \& \mathrm{~b}$; Tatton et al., 1983, and Cheney and Fetz, 1983 for conclusive evidence and discussion). The M2-3 segments of the MER have been reported to be abnormally increased in rigid Parkinsonians (Tatton and Lee, 1975; Mortimer and Webster, 1978; Chan et al., 1979; Rothwell et al., 1982; Berardelli et al., 1983). Importantly, the increased M2-3 segment appears to be strongly correlated with mechanical measures of rigidity (Mortimer and Webster, 1979).

Over the last several years (Bedingham, 1981; Bedingham and Tatton, 1984) response planes have been used to quantitate the MERs. The response planes relate the magnitude of the different segments of the MERs simultaneously to the background level of EMG activity in the stretched muscles and a relevant mechanical parameter such as the initial velocity of the imposed joint movement. Figure 2 presents a schematic of a response plane constructed for the M2-3 segment in a wrist muscle of a normal adult. As shown on the schematic, the $\mathrm{Z}$ axis provides an estimate of the percentage of the alpha motoneuron (MN) pool (for the stretched muscle) active just prior to the imposition of the movement. The vertical or $Y$ axis provides an estimate of the increased percentage of the MN pool recruited by the MER. The $X$ axis can express a number of related mechanical parameters, in this case the logarithm of the angular joint velocity in degrees/sec.

The height above the "floor" of the plot at any point on the surface of the plane provides a measure of the MN response. The planes have established that the increased M2-3 activity of PK rigidity is not dependent on high levels of resting alpha motoneuron activity as previously proposed (Evarts et al., 1979). In fact, PK rigidity and the M2-3 activity which correlates to it can be evoked in muscles with low levels of tonic activity suggesting the increased gain results from altered excitability of interneurons in polysynaptic pathways (see Tatton et al., 1984a).

The planes can be constructed for single trials rather than averaged data and normalized against the maximum EMG responses to peripheral nerve stimulation (see Verrier et al., 1984 for details). Comparable planes constructed for imposed wrist movements stretching flexor carpi radialis (FCR) are 

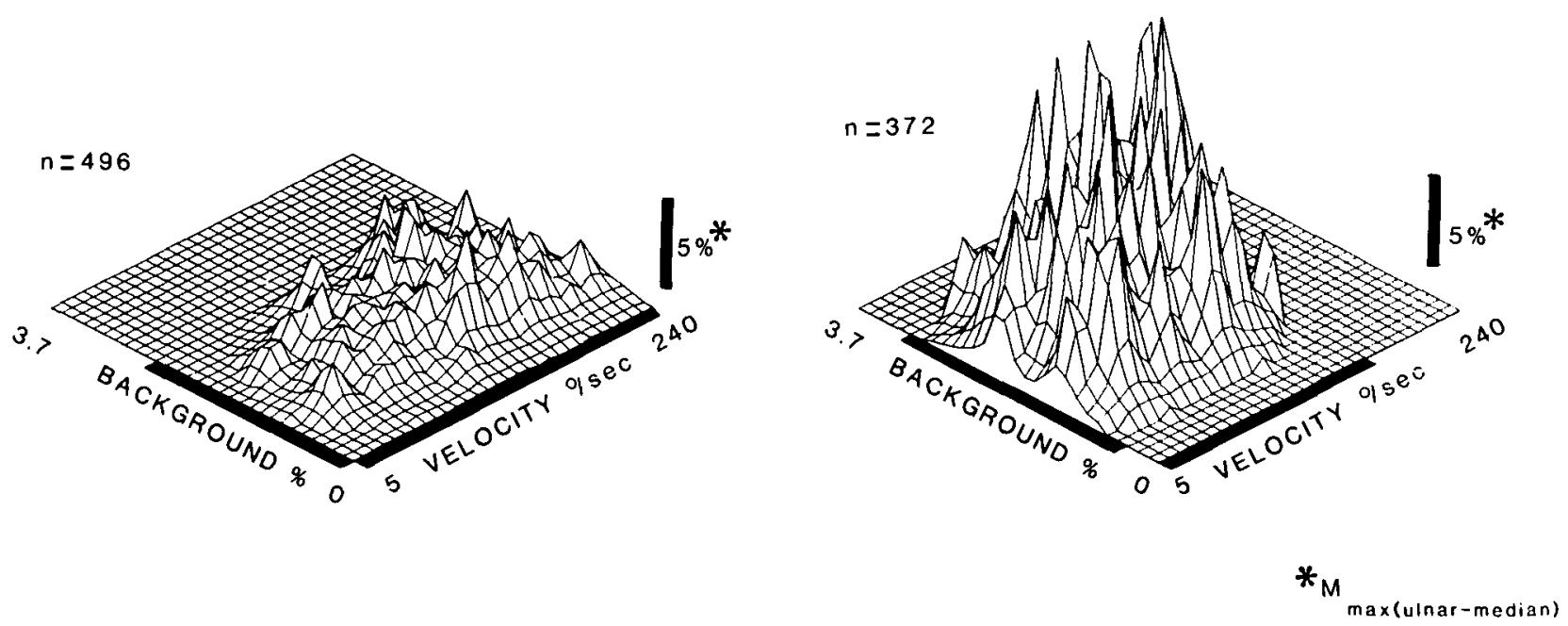

Figure 3 - Response planes of EMG responses in flexor carpi radialis (FCR) in response to imposed wrist displacements over a range of velocities and levels of background EMG in a normal (left panel) and parkinsonian (right panel) patient. The EMG activity was normalized to the maximal $M$ response to nerve stimulation ( $M$ max).

\section{N-METHYL-4-PHENYL-1,2,3,6-TETRAHYDROPYRIDINE TREATED RHESUS}

( $0.33 \mathrm{mg} / \mathrm{kg}$ over 5 days)

Day o(Control) - M2 EDC

$N=272$

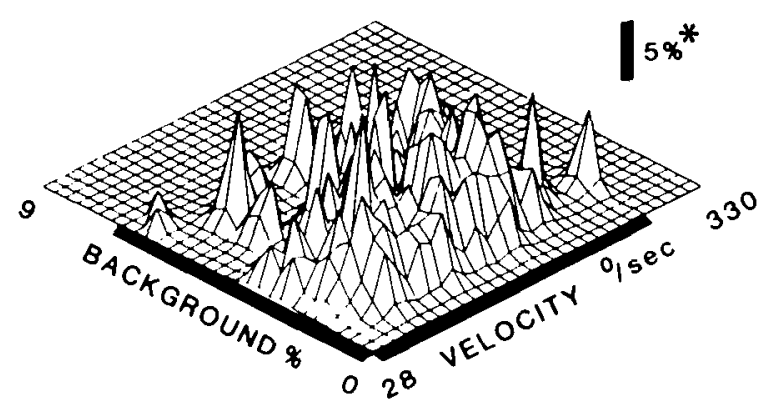

Day 7 - M2 EDC

$N=286$

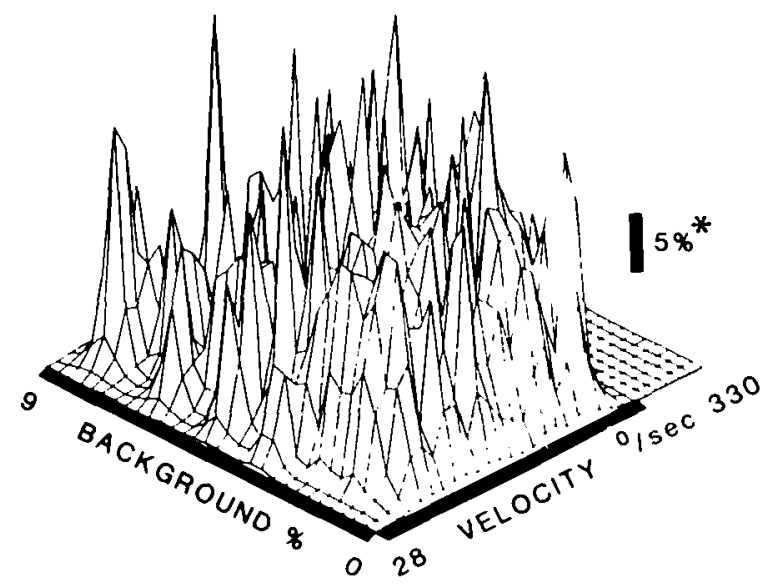

$*_{\text {max(radial })}$

Figure 4-Response planes of EMG responses in extensor digitorum communis (EDC) in response to imposed wrist displacements in a monkey prior to (left panel) and seven days after the initiation of MPTP treatment (right panel). Conventions as in Fig. 3. 
presented in figure 3 for the M2-3 segment in a normal adult (left plane) and an age matched rigid PK (right plane). Note the normal plane is graded with both the level of background EMG and the velocity of the imposed movement. Furthermore, the M2-3 segment of the MER shows a velocity threshold between 20 and 40 degrees/sec and a background EMG threshold of 0.4 to $0.6 \%$ maximum EMG response.

In contrast, the rigid PK shows markedly increased M2-3 segments for the FCR MERs which reach maximum magnitudes 5 to 8 times those of the normal at velocities of $40-60$ degrees $/ \mathrm{sec}$ and well defined responses at velocities as low as 5 degrees/sec irrespective of the level of background EMG. Data such as these attest to the high sensitivity of PK mechanoreceptor-evoked reflexes contributing to the generation of the M2-3 segment.

Based on the recent research implicating the motor cortex in the generation of the M2-3 segment recorded in wrist musculature (see above) and new findings (Bedingham and Tatton, 1983) demonstrating that motor cortical neurons are strongly responsive to the higher derivatives of imposed joint movement, acceleration and jerk (the derivative of acceleration), we have proposed that high "gain" in a transcortical "predictive" feedback system (Tatton et al., 1984b) may contribute to the generation of the increased M2-3 segments and PK rigidity. The proposal requires abnormal levels of outflow of basal activity to the motor cortex which is in accord with the findings in primate models of PK rigidity (Filion, 1979; Pechadre et al., 1976; Poirier, 1960; Tatton et al., 1979).

\section{Mechanoreceptor-evoked Reflexes following MPTP treatment}

Both human (Davis et al., 1979; Langston et al., 1983 and this volume) and subhuman primates (Burns et al., 1983 and this volume) exposed to 1-methyl-4 phenyl-1,2,3,6-tetra hydropyridine (MPTP) develop a syndrome clinically indistinguishable from Parkinson's disease. There appears to be complete destruction of the $\mathrm{SN}_{\mathrm{c}}$ by this agent resulting in CSF and regional brain alterations in dopamine and homovanillic acid concentrations similar to those in idiopathic PK (see Burns, this volume).

Figure 4 presents single trial response planes for a rhesus monkey treated with MPTP $(0.33 \mathrm{mg} / \mathrm{kg}$ in divided doses over five days). The plane on the left was constructed for the M2 segment of the MER recorded in extensor digitorum communis (EDC) on the day prior to the initiation of the treatment. The plane on the right was constructed for the same muscle on the seventh day of the program. The animal had not received treatment with L-dopa prior to these recordings and presented a Parkinsonian picture identical to that reported by Burns et al. (1983). These initial findings indicate that the MPTP primate model shows increased long latency segments as a correlate to rigidity similar to human PKs (compare figures 3 and 4). Although these findings represent the first data indicating electrophysiogical homology in motor deficits between the MPTP model and idiopathic PK, they support the contention that the model may offer a unique experimental "window" through which the abnormal mechanisms linking striatal dopamine depletion to rigidity, bradykinesia and other motor program dysfunctions (see below) found in Parkinson's disease can be determined.

\section{Motor Programs and "Predictive" Sensory Input in Parkinson's Disease}

Flowers (1975, 1976 and 1978) studied normals and PKs using a series of paradigms in which upper limb control of a joystick was used to study tracking of a moving circle on an oscilloscope screen. Various tracking waveforms were examined and clever maneuvers were employed, where the accuracy of the tracking was fed back visually by a spot on the screen which was intermittently blanked, removing visual feedback. Accepting the major interpretive limitation that the interposition of the oscilloscope creates an artificial visual control situation, the research revealed interesting differences between PKs and normals: 1) preprogramed or "ballistic" PK movements were slow and PKs showed a decreased repertoire of movements; 2) PKs did not increase velocity proportional to amplitude of the required movement; 3) PK movements were "broken" into two or more smaller movements once a given amplitude was exceeded;4) the movement went "off track" when visual feedback was briefly interrupted, suggesting sensory input from mechanoreceptors was not sufficient to maintain the movement's course; and 5) PK performance did not improve with repetition. Flowers concluded that the integration of sensory information is an essential aspect of preprogrammed movements, and that PKs have a defect in their capacity to use kinesthetic feedback to "predict" the subsequent course of a movement.

Recent research in our laboratory may be pertinent to Flowers' hypothesis. In the awake cat (Bedingham and Tatton, 1983), we have studied the responses of single motor cortical neurons (MCNs) in area 4 into three different elbow movements: constant velocity ramps, sinusoids, and step load imposed displacements. The research has shown that weighted coefficients of a third order differential equation $\left(\mathrm{K}_{\frac{3}{3}} \frac{\mathrm{d}^{3} \theta}{\mathrm{dt}^{3}}\right.$, jerk; $\mathrm{K}_{2} \frac{\mathrm{d}^{2} \theta}{\mathrm{dt}^{2}}$, acceleration; $K_{1} d \theta$, velocity; and $K_{0} 0$, position; where $\theta$ is the joint $\overline{\mathrm{dt}}$

angle) for the imposed movements can be used to reliably describe the time course of the response, and are constant for each MCN irrespective of the type of movement imposed. Importantly MCN's in motor cortical areas projecting to the spinal cord as determined by microstimulation showed a preponderance of responsiveness to the higher derivative of the imposed movements (acceleration and jerk).

The preponderance of higher derivative (jerk and acceleration) responsiveness can be hypothesized to confer a predictive capacity on the MCNs if "summed" with programmed inputs. Movement "errors" estimated by their initial jerk or acceleration components would be "predicted" by the MCN's responses to trajectory deviations thereby potentially compensating for the conduction lags and delays in tension generation inherent in neural feedback mechanisms. That is, the responsiveness to higher derivatives would strongly activate MCNs prior to major deviations from a centrally-programmed trajectory, while in comparison velocity component-dominated MCNs would not respond as predictively.

Modelling of our own monkey MCN data (Tatton et al., 1979) together with Cheney and Fetz's (1983) spike-triggered identified corticomotoneuronal cells has led to two related hypotheses, now testable in MPTP monkeys: 1) that the increased M2-3 activity in PK is at least partially due to an overcompensated and faulty predictive feedback system involving MCNs (see above); and 2) the PK movement defects described by Flowers may result from the same dysfunction. Accordingly bradykinesia, loss of motor program repertoire, etc. in PKs should be correlated with the relative increase in their M2-3 components as judged from the response planes. Three cautions must be emphasized 


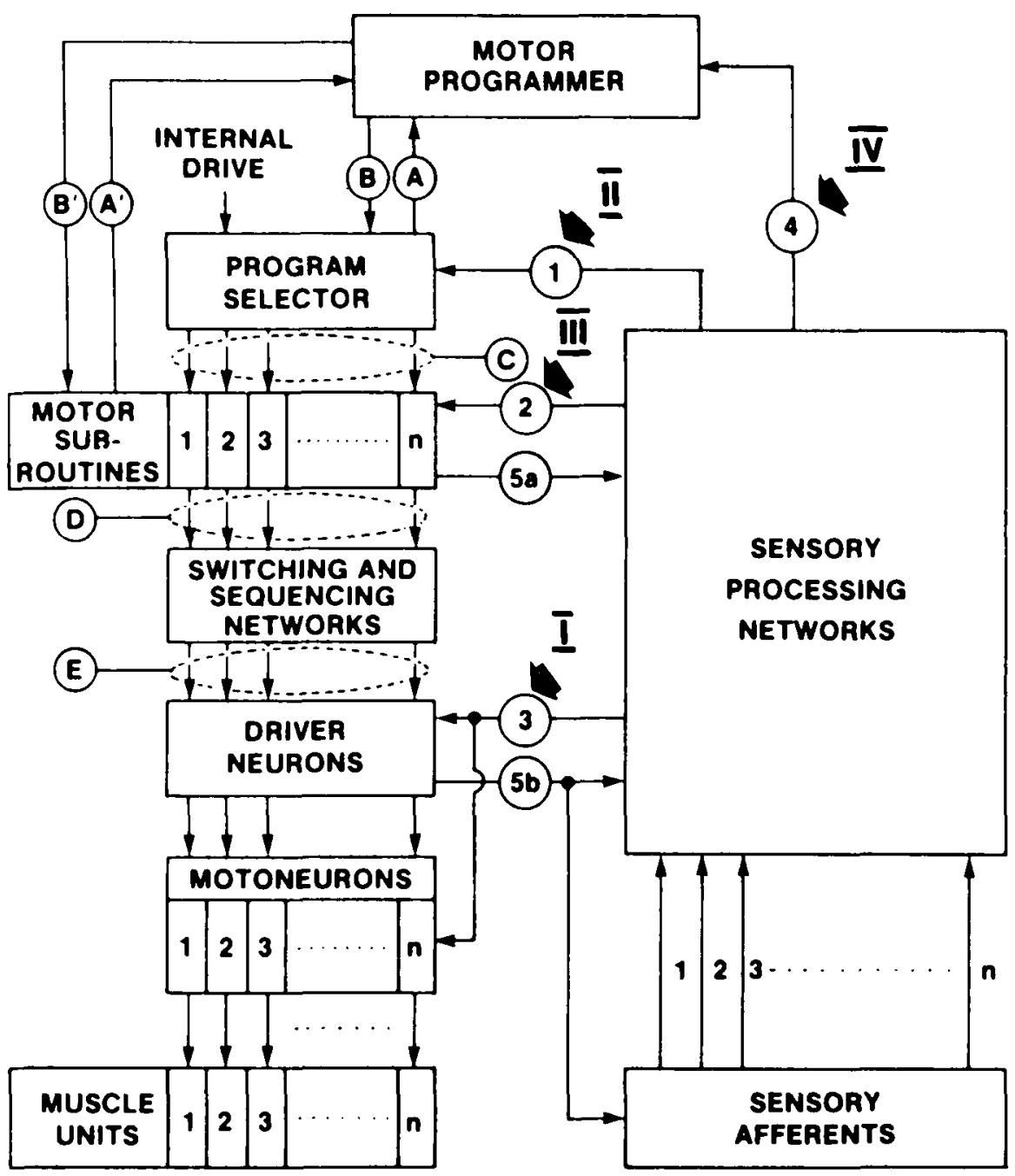

Figure 5 - Schematic representation of sensory and motor components of a hypothetical nervous system.

On the left, the boxes represent the neuronal networks involved in the initiation, generation and execution of motor programs. and are connected by neuronal pathways (arrows) designated by the letters A through E. $A, A$ ' and $B, B$ ' represent pathways by which a "motor programmer" is informed of ongoing movements and can thus update, modify or learn new movements and select the appropriate subroutines directly ( $\left.B^{\prime \prime}\right)$ or via a "program selector" (C). The components (subroutines) of the desired movement are organized by a set of "switching and sequencing networks" (via $D$ ) and the resulting activity played out (E) via "driver neurons" to the motoneurons for execution by muscle fibres.

On the right, the "sensory processing networks" which interact with the motor apparatus are illustrated by the numbered linkages (1-5). Thus, afferent activity can initiate program selection for a desired movement (1), advance the program to the next subroutine (2), modify the "gain" of the program output (3), and in combination with $A$ and $A$ '. inform the "motor programmer" whether modifications to the movement are required (4). Further, output from the motor apparatus $(5 a, b)$ can "gate" or feedback to the sensory processing networks.

The Roman numerals (I-IV) indicate the levels at which the defects in PK could occur. Note that they all fall on the "sensory" side of the scheme and would interfere with linkages 2-4 defined above. (See Bruce and Tatton. 1981 and text for further details). (Reproduced and modified by permission of the National Research Council of Canada from the Canadian Journal of Physiology and Pharmacology, Volume 59, 1981.)

before applying these findings to Flowers' observations: 1) the "derivative" responses in the cat motor cortex may not apply to subhuman primates or humans and must be reexamined in a primate species (to date only a small population of monkey MCN's have been analyzed); 2) if present in the monkey, the "higher derivative" MCNs must be shown to project to motoneurons innervating appropriate muscles for predictive correction; and 3) the results were gathered using movements imposed at a single joint, in a single plane. To become valid, MCN activity must be shown to have the same "higher derivative" responses during multijoint, three-dimensional movements.

In order to more fully elucidate the hypotheses presented above the schematic in figure 5 was modified from a general model proposed for interactions between motor programs and sensory input (Tatton and Bruce, 1981). Accepting that higher derivative mechanoreceptor information is utilized at all levels of the interactions schematized in the diagram, then all of the PK movement disorders described above could be accounted for by defective "predictive" processing by the central nervous system:

1) increased gain of higher derivative mechanoreceptive feedback through structures such as the motor cortex could account for rigidity (arrow I in figure 5);

2) the normal or minimally increased reaction times as compared to the prolonged movement times in PKs (Evarts et al., 1981) indicates initiation of motor programs is not defective (arrow II in figure 5); 
3) the separation of movements into series of smaller movements (see Flowers' 3rd defect above) together with the limited movement repertoire in PKs (Flowers' 1st and 2nd defects above) appears to reflect access to a decreased subset of motor subroutines (arrow III in figure 5);

4) the inability to maintain the expected course of tracking movement without visual feedback (arrow I in figure 5); and

5) failure of improved performance with repetition (arrow IV in figure 5).

In closing the MPTP model may provide a means to test these hypotheses and relate the defects schematized in figure 5 to dysfunctions in specific neuronal connections in the structures presented in figure 1.

\section{REFERENCES}

Allum JHJ (1976) Responses to load disturbance in human shoulder muscles: The hypothesis that one component is a pulse test information signal. Exp. Brain Res. 22: 307-326.

Bedingham W (1981) Input-Output Properties of the Human Wrist Reflex - A Model for Studying Neuromotor Diseases. M.Sc. Thesis, University of Toronto.

Bedingham W, Tatton WG (1983) Kinesthetic "encoding" by motor cortical neurons in the awake cat. Soc. Neurosci. Abstr. 9, 1082.

Bedingham W, Tatton WG (1984) The dependence of EMG responses evoked by imposed wrist displacements on pre-existing levels of activity in the stretched muscles. Canadian J. Neurol. Sci. (in press).

Berardelli A, Sabra AF, Hallett M (1983) Physiological mechanisms of rigidity in Parkinson's disease. J. Neurol. Neurosurg. and Psychiat., 46: $45-53$.

Burns SR, Chiueh CC, Markey SP, Ebert MH, Jacobowitz DM, Kopin IJ (1983) A primate model of Parkinsonism: Selective destruction of dopaminergic neurons in the pars compacta of the substantia nigra by 1-methyl-4 phenyl-1,2,3,6-tetrahydropyridine. Proc. Nat. Acad. Sci. U.S.A. 80: 4544-4550.

Chan CWY, Kearney RE, Melvill-Jones G (1979) Tibialis anterior response to sudden ankle displacements in normal and Parkinsonian subjects. Brain Res. 173: 303-314.

Cheney PD, Fetz EE (1983) Primate cortical motoneuronal cells contribute to long latency stretch reflexes. J. Physiol. (Lond.), in press.

Davis GC, Williams AC, Markey SP, Ebert MH, Caine ED, Reichert CM, Kopin IJ (1979) Chronic Parkinsonism secondary to intravenous injection of meperidine analogues. Psychiat. Res. I: 249-254.

DeLong MR, Georgopoulos AP (1981) Motor functions of the basal ganglia. In: Handbook of Physiology. Section I: The Nervous System. Eds. Brookhart, J.M. and Mountcastle, V.B., Vol. 2, part 2, pp. 1017-1061.

DeLong MR, Crutcher MD, Georgopoulos P (1983) Relations between movement and single cell discharge in the substantia nigra of the behaving monkey. J. Neurosci. 3: 1599-1606.

Evarts EV, Teravainen H, Beuchert DE, Calen DB (1979) Pathophysiology of motor performance in Parkinson's disease. In: Dopaminergic Ergot Derivaties and Motor Functions. Ed. K. Fuxe and D.B. Calne, London: Pergamon, pp. 45-59.

Evarts EV, Teravainen H, Calne DB (1981) Reaction time in Parkinson's disease. Brain, 104: 167-186.

Filion M (1979) Effects of interruption of the nigrostriatal pathway and of dopaminergic agents on the spontaneous activity of globus pallidus neurons in the awake monkey. Brain Res. 178: 425-441.

Flowers K (1975) Ballistic and corrective movements in an aiming task: Intention tremor and Parkinsonian movement disorders compared. Neurol. 25: 413-421.

Flowers K (1978) Some frequency response characteristics of Parkinsonism in pursuit tracking. Brain, 101: 19-34.

Flowers K (1976) Visual 'closed-loop' and 'open-loop' characteristics of voluntary movement in patients with Parkinsonism and intention tremor. Brain, 99: 269-310.
Georgopoulos AP, DeLong MR, Crutcher MD(1983) Relations between parameters of step-tracking movements and single cell discharge in the globus pallidus and subthalamic nucleus of the behaving monkey. Neurosci. 3: 1586-1598.

Gilman S, Carr D, Hollenberg J (1976) Kinematic effects of deafferentation and cerebellar ablation. Brain, 99: 311-330.

Hornykiewicz O (1963) Die Topische Lokalisation Und Verhalten Von Noradrenalin Und Dopamin (3-Hyoroxytyramin) in der Substantia Nigra Des Normalen Und Parkonsonkranken Menschen. Wien. Klin. Wschr. 75: 309-312.

Kupfermann I, Weiss KR (1978) The command neuron concept. Behav. Brain Sci. I: 3-39.

Lamarre Y, Bioulac B, Jacks B (1978) Activity of precentral neurones in conscious monkeys: effects of deafferentiation and cerebellar ablation. J. Physiol. (Paris) 74: 253-264.

Langston JW, Ballard P, Tetrud JW, Irwin I (1983) Chronic Parkinsonism in humans due to a product of meperidine-analog synthesis. Science. 219: $979-980$.

Lee RG, Tatton WG (1982) Long latency reflexes to imposed displacements of the human wrist: dependence on duration of movement. Exp. Brain Res. 45: 207-216.

Lenz FA, Tatton WG, Tasker RR (1983a) Electromyographic response to displacement of different forelimb joints in the squirrel monkey. J. Neurosci. 3: 783-794.

Lenz FA, Tatton WG, Tasker RR (1983b) The effect of cortical lesions on the electromyographic response to joint displacement in the squirrel monkey forelimb. J. Neurosci. 3: 795-805.

Liles SL (1983) Activity of neurons in the putamen associated with wrist movements in the monkey. Brain Res. 263: 156-161.

Marsden CD, Merton PA, Morton HB (1972) Servo-action in human voluntary movement. Nature 238: 140-143.

Marsden CD, Merton PA, Morton HB (1976) Stretch reflex and servoaction in a variety of human muscles. J. Physiol., (Lond.) 259: $531-560$.

Mortimer JA, Webster DD (1978) Relationships between quantitative measures of rigidity and tremor and the electromyographic responses to load perturbations in unselected normal subjects and Parkinson patients. In: Progress in Clinical Neurophysiology, Vol. 4: Cerebral Motor Control in Man: Long Loop Mechanisms. ed. Desmedt, J.E., pp. 342-360, Karger, Basel.

Mortimer JA, Webster DD (1979) Evidence for a quantitative association between EMG stretch responses and Parkinsonian rigidity. Brain Res. 162: 169-173.

Mountcastle VB, Lynch JC, Georgopoulos A, Sakata H and Acuna C (1975) Posterior parietal association cortex of the monkey: command functions for the operations within extrapersonal space. J. Neurophysiol. 38: 871-908.

Pechadre JC, Larochelle L, Poirer LJ (1976) Parkinsonian akinesia, rigidity and tremor in the monkey. J. Neurol. Sci. 28: 147-157.

Poirer LJ (1960) Experimental and histological study of midbrain dyskinesia. J. Neurophysiol. 23: 534-551.

Rothwell JC, Traub MM, Marsden CD (1982) Automatic and "voluntary" responses compensating for disturbances of human thumb movements. Brain 248: 33-41.

Schultz W (1982) Depletion of dopamine in the striatum as an experimental model of Parkinsonism: direct affects and adaptive mechanisms. Prog. Neurobiol. 18: 121-166.

Schultz W, Ruffieux A, Aebiseher P(1983) The activity of pars compacta neurons of the monkey substantia nigra in relation to motor activation. Exp. Brain Res. 51: 377-387.

Taub E, Berman AJ (1968) Movement and learning in the absence of sensory feedback. I $n$ : The Neuropsychology of Spatially Oriented Behavior, edited by S.J. Freedman. Homewood, IL: Dorsey, P.L.P. 174-192.

Taub E, Goldberg IA, Taub P (1975) Deafferentation in monkeys: pointing at a target without visual feedback. Exp. Neurol. 46: 178-186.

Tatton WG, Bruce IC (1981) Comment: A schema for the interactions between motor programs and sensory input. Can. J. Physiol. Pharmacol. 59: 691-699.

Tatton WG, Lee RG (1975) Evidence for abnormal long-loop reflexes in Parkinsonian patients. Brain Res. 100: 67I-676.

Tatton WG, Bawa P, Bruce IC (1979) Altered motor cortical activity in motor cortical rigidity. In: The Extrapyramidal System, L.J. Poirier, T.L. Sourkes and P.J. Bedard, Eds., Adv. Neurol. 10: 141-160. 
Tatton WG, North AGE, Bruce IC, Bedingham W (1983) Electromyographic and motor cortical responses to imposed displacements of the cat elbow: Disparities and homologies with those of the primate wrist. J. Neurosci. 3: 1807-1817.

Tatton WG, Bedingham W, Verrier MC, Blair RDG (1984a) Characteristic alterations in the responses to imposed wrist displacement in Parkinsonian rigidity and dystonia musculorum deformans. Can. J. Neurol. Sci., In press.

Tatton WG, Bedingham W, Verrier M, Bruce IC, Blair RDG (1984b) Abnormalities of Mechanoreceptor-Evoked Electromyographic Activity in Central Motor Disorders. A Struppler Ed. Thieme Publishers, Stutgart, Germany. In Press.
Verrier MC, Tatton WG. Blair RDG (1984) Characteristics of long latency responses to imposed limb displacement in cerebrovascular disease. Can. J. Neurol. Sci., In press.

Wiesendanger $M$ (1981) Organization of secondary motor areas of cerebral cortex. Handbook of Physiology. Section I: The Nervous System. Eds. Brookhart, J.M. and Mountcastle, V.B. Vol. 2. Part 2, pp. 1121-1148.

Wiesendanger M, Miles TS (1982) Ascending pathway to low threshold muscle afferents to the cerebral cortex and its possible role in motor control, Physiol. Rev. 62: 1234-1270. 